\title{
Evaluation of a Group Cue-Exposure Treatment for Opiate Addicts
}

\author{
Mónica Bernaldo de Quirós Aragón, Francisco J. Labrador, and Fernando de Arce \\ Universidad Complutense de Madrid
}

Twenty-four detoxified opiate addicts were randomized to an experimental group and a control group to evaluate efficacy of a group cue-exposure treatment to reduce or extinguish classically conditioned responses to drug-related stimuli. Assessment included psychophysiological responses (skin temperature, skin conductance level-SCL-, and heart rate) to a videotape and subjective measures (subjective craving, positive and negative affect) before and after the videotape. The experimental group received a group cueexposure program to drug-related stimuli that comprised twelve treatment sessions administered three times weekly. The treatment program significantly reduced conditioned responses to drug-related stimuli, as measured by SCL and positive affect.

Key words: craving, cue-exposure, psychophysiological assessment, addictions

\begin{abstract}
Veinticuatro adictos a los opiáceos, ya desintoxicados, fueron asignados de forma aleatoria a un grupo experimental y un grupo control para evaluar la eficacia de un tratamiento de exposición para reducir o extinguir las respuestas condicionadas a los estímulos asociados con la droga. La evaluación incluyó las respuestas psicofisiológicas (temperatura periférica, nivel de conductancia dermoeléctrica y frecuencia cardiaca) emitidas ante la presentación de un video, así como medidas subjetivas (grado de "deseo" subjetivo, afecto positivo y negativo) antes y después de la presentación del video. El grupo experimental recibió un programa de exposición en grupo a estímulos relacionados con la droga, consistente en doce sesiones de tratamiento con una periodicidad de tres veces por semana. El programa de tratamiento redujo de forma significativa las respuestas condicionadas a los estímulos relacionados con la droga, de acuerdo con las medidas de nivel de conductancia electrotérmica y afecto positivo.

Palabras clave: "deseo", exposición a claves, evaluación psicofisiológica, adicciones
\end{abstract}

Correspondence should be addressed to Mónica Bernaldo de Quirós Aragón, Facultad de Psicología, Universidad Complutense de Madrid, Campus de Somosagüas, 28223 Madrid (Spain). Phone: 34-91-3943126. Fax: 34-91-3943189. E-mail: mbquirosmb@ hotmail.com. 
Once addicts are detoxified, they sometimes report craving and withdrawal symptoms to several drug-related stimuli. Drug-related stimuli elicit craving and withdrawal symptoms by repeated drug administration in the presence of these stimuli.

The proposal put forward by Rankin, Hodgson, and Stockwell (1979) to operationalize the concept of craving established the starting point to facilitate its measurement. In a review of the studies which have assessed craving to drug related stimuli (Bernaldo de Quirós, Arce, \& Labrador, 2002), it was concluded that: (a) It is important to assess subjective and psychophysiological measures; (b) subjective measures should include subjective craving and emotional states; (c) the reviewed studies mainly used as psychophysiological measures: heart rate, skin conductance level (SCL), and skin temperature. Evidence has been found of significant increases in skin conductance to drug-related stimuli in detoxified addicts (Childress, McLellan, \& O’Brien, 1984, 1986a, 1986b; Legarda, Bradley, \& Sartory, 1987, 1990; Sideroff \& Jarvik, 1980). SCL is used as an arousal indicator and it could be a craving indicator. Childress et al. observed a significant decrease in skin temperature to drug-related stimuli and they state that skin temperature was the most specific measure to drug-related stimuli. Results are not so clear with regard to heart rate; some studies have found evidence of an increase in heart rate to drug-related stimuli (Arce, 1995; Legarda, 1992; Muñoz-Rivas, 1997; Sideroff \& Jarvik, 1980), however, others have not observed significant differences (Childress et al., 1984, 1986a; 1986b; Legarda et al., 1987).

The use of cue-exposure techniques has been proposed to extinguish craving to drug-related stimuli in detoxified addicts. Conditioned responses may be extinguished or reduced by means of a systematic, gradual exposure to drugassociated cues.

However, previous results have been disappointing (O’Brien, Greenstein, Ternes, McLellan, \& Grabowski, 1979; Childress, et al., 1984, 1986a). Childress et al. (1986b) reported that some addicts showed conditioned responses to drug-related stimuli only if they were in a particular emotional state. These authors subsequently developed a new procedure that proved more effective. The addicts were exposed to drug-related stimuli after the hypnotic induction of four mood states (McLellan, Childress, Ehrman, \& O'Brien, 1986). The influence of cognitive factors may also be able to significantly modulate the efficacy of a cueexposure treatment. Addicts often report changes in their thoughts about drug-related stimuli after treatment. Childress (1991) obtained positive results using active strategies (training in alternative responses and cognitive techniques) to cope with conditioned responses.

Cue-exposure treatment may aid relapse prevention, not only by extinction of conditioned responses, but also by changing outcome and self-efficacy expectancies (Drummond, Troy, \& Glautier, 1990). Likewise, the need of integrating cue-exposure techniques in broader programs of coping-skills training is acknowledged. Marlatt (1990) pointed out that a comprehensive program of relapse prevention should combine cue-exposure techniques with coping-skills training, in real or simulated high-risk situations.

Although several studies have obtained promising results, integration of cue-exposure methods for addictive disorders has been scarce in Spain. The public institutions for opiateaddict treatment must respond to high demand for treatments and a large number of users. Carrying out cue-exposure treatment individually requires large resources, as sessions should take place at least three times a week.

The aim of the present study is to assess the efficacy of a group cue-exposure procedure to reduce craving to drug-related stimuli. It was expected that the cue-exposure treatment would reduce the decrease in skin temperature and the increase in SCL and heart rate to drug-related scenes. It was also expected that the cue-exposure program would reduce the increase in subjective craving and negative affect and the decrease in positive affect after watching drug-related scenes.

\section{Method}

\section{Participants}

A total of 24 individuals participated in this study. In the experimental group, there were 12 participants, 8 men and 4 women (mean age $=26.7$ years old; range 17-38 years), who had used heroin for an average of 6.58 years (range 2-17 years), and had been abstinent for an average of 2.8 months (range 1-6 months). In the control group, there were 12 participants, 10 men and 2 women, (mean age $=28.08$ years old; range 21-34 years), who had used heroin for an average of 5.58 years (range 1-18 years), and had been abstinent for an average of 4.3 months (range 16 months).

Participants were patients from the Drug Dependence Center of Alcorcón, a public out-patient center near Madrid. We selected detoxified patients who were addicted to heroin, with an administration route of inhalation of fumes, and in the first six months of abstinence. To rule out associated psychiatric problems, patients were clinically screened with the Global Severity Index (GSI) of the Symptom CheckList-90-R (SCL-90-R; Derogatis, 1983).

The 24 remaining detoxified opiate addicts were randomized to an experimental group and a control group.

\section{Psychophysiological measures}

The participants' skin temperature, SCL, and heart rate were measured while they were exposed to a videotape that showed scenes including drug-related stimuli. 
The psychophysiological measures were recorded using a J\&J Physiological Personal Computer System by J\& Enterprises (1988). Measures were recorded and averaged every 3 seconds.

SCL was measured with two $\mathrm{Ag} / \mathrm{Ag} \mathrm{Cl}$ electrodes placed on the distal phalanxes of the index and middle fingers of the participant's left hand; heart rate was measured with a photoplethysmograph placed on the thumb of the left hand, and skin temperature, with a thermosensitive transducer placed on the ring finger of the same hand.

The videotape was recorded by the authors (Arce, Bernaldo de Quirós, \& Labrador, 1994). It showed drug-related scenes (withdrawal syndrome, drug-seeking-and-buying, fumeinhalation, overdose) and a non-drug-related scene (erotic scene) presented for 90 seconds each, with an initial base line period of 90 seconds, as displayed in Table 1.

Drug related scenes showed different drug-related situations in order to identify different activation patterns. There was a return base line period of 60 seconds after each scene to permit the activation remission produced by the prior scene.

\section{Subjective measures}

Subjective craving was measured before and after watching the videotaped scenes by a Craving Scale which consisted of a 0-100 scale. Before and after watching the videotape scenes, participants were asked to rate the degree of craving they felt.

Negative and positive affect were assessed before and after watching the videotaped scenes with the Positive and Negative Affect Schedule (PANAS; Watson, Clark, \&
Tellegen, 1988) which had 10 items. Before and after watching the videotape with drug-related stimuli, participants were asked to rate on a 5-point scale the extent to which they experienced each mood state. The points of the scale were labeled very slightly or not at all (1), a little (2), moderately (3), quite a bit (4) and very much (5).

\section{Procedure}

A psychophysiological assessment was conducted, the procedure of which is described in Table 1.

Participants who were assigned to the experimental group were given an appointment for the first treatment session. Participants who were assigned to the control group were informed that another assessment would be carried out a month later.

The control group received the routine treatment program, which included individual and group sessions aimed at relapse prevention, learning to detect high risk situations, as well as social skills training.

The experimental group received the same routine treatment program as the control group, plus a gradual cueexposure program to drug-related stimuli. The cue-exposure program was carried out in groups of 6 participants, directed by two therapists. The program comprised twelve treatment sessions, three sessions per week, for four weeks. The duration of each cue-exposure session was 60 minutes (sessions 1, 2, and 3) or 75 minutes (sessions 4 to 12).

In the first treatment session, the program was presented. The addicts were informed of the following: results of the assessment, the aim of the program, the importance and mechanisms of cue-exposure techniques, and the content of

Table 1

Psychophysiological Assessment

1. Accommodation period $(15 \mathrm{~min})$

2. Placement of the electrodes and adaptation period (5 min)

- Questionnaires: PANAS and Craving Scale

3. Baseline (BL) (90 s)

4. Videotape

- Erotic scene (90 s)

- Return to baseline (60 s)

- Withdrawal syndrome (90 s)

- Return to baseline (60 s)

- Drug-seeking-and-buying (90 s)

- Return to baseline (60 s)

- Fume-inhalation (90 s)

- Return to baseline (60 s)

- Shoot-out (90 s)

- Return to baseline (60 s)

- Overdose (90 s)

5. Questionnaires: Craving Scale and PANAS

- Relaxation (8 min)Uncommon abnormalities 
the sessions. The session ended with induced relaxation. During the second treatment session, gradual exposure to drug-related stimuli commenced, starting with simple stimuli (tinfoil, cigarette lighter, pipe, a bag of heroin) and proceeding to complex stimuli (administration ritual, induction of emotional states, areas related to drug-seeking and buying). The content of the sessions is described in Table 2.
After the cue-exposure program and at 6-month followup, all the participants were re-assessed. During the treatment sessions, those participants who used heroin were eliminated from the program: three participants from the experimental group and six participants from the control group. The final results considered included 9 participants in the experimental group and 6 participant in the control group.

Table 2

Structure of the Cue-Exposure Program (12 Sessions)

S 1: Presentation

Relaxation

S 2: Cue-exposure to tinfoil

Negative consequences of using drugs

Relaxation

S 3: Cue-exposure to a cigarette lighter and pipe

Positive consequences of abstinence

Relaxation

S 4: Cue-exposure to a bag of heroin

Negative and positive consequences of using drugs and abstinence

Relaxation

S 5: Cue-exposure to administration ritual

Alternative behaviors to using drugs

Relaxation

S 6: Induction of a euphoric emotional state and cue-exposure to administration ritual

Coping behaviors

Relaxation

S 7: Induction of a sad emotional state and cue-exposure to administration ritual Coping behaviors

Relaxation

S 8: Induction of an anxious emotional state and cue-exposure to administration ritual Coping behaviors

Relaxation

S 9: Induction of an angry emotional state and cue-exposure to administration ritual Coping behavior

Relaxation

S10: Induction of a bored emotional state and cue-exposure to administration ritual Coping behaviors

Relaxation

S11: Cue-exposure to areas where they buy drugs (videotape)

Assertive behaviors

Relaxation

S12: Cue-exposure to areas where they buy drugs (in vivo)

Relaxation 


\section{Data Analysis}

Descriptive statistics were calculated for the experimental and control groups. These statistics appear in Table 3.

In order to analyze data from psychophysiological variables (skin temperature, SCL, and heart rate), first, the mean of each response was obtained for each participant at three intervals during the video: baseline, drug-seeking-and-buying, and fume inhalation. We selected drug-seeking-and buying and fume inhalation scenes because they were related to the cue-exposure treatment. To obtain the means, only the last 30 seconds of each interval were used in order to avoid the initial moments of each scene in which activation could be minimal.
A difference score was computed for each psychophysiological measure of each video scene. The change index of these responses was obtained by subtracting the mean of fume inhalation and drug-seeking-and-buying from the mean of baseline interval.

To analyze subjective craving and positive and negative affect, a change index for each response was obtained. The scores obtained after watching the videotape were subtracted from the scores obtained on these scales prior to watching the videotape, for each response.

Data were analyzed with the Statistical Package for Social Sciences (SPSS-PC+). Because of the reduced number of participants, nonparametric tests were chosen.

Table 3

Descriptive Features of the Sample

\begin{tabular}{|c|c|c|c|c|c|c|c|c|c|c|c|}
\hline & & \multicolumn{5}{|c|}{ Experimental Group } & \multicolumn{5}{|c|}{ Control Group } \\
\hline & & $M$ & $S D$ & Range & $N$ & $\%$ & $M$ & $S D$ & Range & $N$ & $\%$ \\
\hline & Male & & & & 8 & 66.6 & & & & 10 & 83.3 \\
\hline & Female & & & & 4 & 44.4 & & & & 2 & 16.7 \\
\hline \multicolumn{2}{|c|}{ Age (years) } & 26.75 & 6.91 & $17-38$ & & & 28.08 & 4.5 & $21-34$ & & \\
\hline \multicolumn{2}{|c|}{ Duration of heroin use (years) } & 6.58 & 4.69 & $2-12$ & & & 5.58 & 5.66 & $1-18$ & & \\
\hline \multicolumn{2}{|c|}{ Duration of abstinence (months) } & 2.83 & 1.4 & $1-6$ & & & 4.33 & 1.87 & $1-6$ & & \\
\hline \multicolumn{2}{|c|}{ GSI } & 0.68 & 0.54 & $0.11-1.56$ & & & 0.46 & 0.29 & $0.2-1.28$ & & \\
\hline
\end{tabular}

Note . GSI = Global Severity Index of the SCL-90-R (Derogatis, 1983).

Table 4

Psychophysiological Responses, Means and Standard Deviations (in Brackets)

\begin{tabular}{|c|c|c|c|c|c|c|}
\hline & \multicolumn{2}{|c|}{ PRETREATMENT } & \multicolumn{2}{|c|}{ POSTTREATMENT } & \multicolumn{2}{|c|}{ FOLLOW-UP } \\
\hline & Experimental & Control & Experimental & Control & Experimental & Control \\
\hline \multicolumn{7}{|l|}{ SKIN TEMPERATURE } \\
\hline Base line & $\begin{array}{l}29.41 \\
(4.51)\end{array}$ & $\begin{array}{l}29.82 \\
(4.23)\end{array}$ & $\begin{array}{l}25.70 \\
(5.09)\end{array}$ & $\begin{array}{l}28.87 \\
(4.68)\end{array}$ & $\begin{array}{l}34.75 \\
(1.04)\end{array}$ & $\begin{array}{l}34.38 \\
(0.81)\end{array}$ \\
\hline Inhalation-fume scene & $\begin{array}{c}30.3 \\
(4.39)\end{array}$ & $\begin{array}{l}30.27 \\
(4.40)\end{array}$ & $\begin{array}{l}27.66 \\
(5.13)\end{array}$ & $\begin{array}{c}31.4 \\
(3.99)\end{array}$ & $\begin{array}{l}35.12 \\
(0.81)\end{array}$ & $\begin{array}{l}34.95 \\
(1.01)\end{array}$ \\
\hline Drunk-seeking-and-buying scene & $\begin{array}{l}30.04 \\
(4.28)\end{array}$ & $\begin{array}{l}30.45 \\
(4.38)\end{array}$ & $\begin{array}{l}27.12 \\
(4.81)\end{array}$ & $\begin{array}{l}31.18 \\
(3.81)\end{array}$ & $\begin{array}{l}34.95 \\
(1.04)\end{array}$ & $\begin{array}{l}34.49 \\
(1.69)\end{array}$ \\
\hline \multicolumn{7}{|l|}{$S C L$} \\
\hline Base line & $\begin{array}{l}10.13 \\
(7.73)\end{array}$ & $\begin{array}{c}9.73 \\
(3.64)\end{array}$ & $\begin{array}{c}5.83 \\
(2.98)\end{array}$ & $\begin{array}{c}3.86 \\
(0.01)\end{array}$ & $\begin{array}{c}9.73 \\
(2.22)\end{array}$ & $\begin{array}{c}9.38 \\
(0.04)\end{array}$ \\
\hline Inhalation-fume scene & $\begin{array}{l}12.01 \\
(9.86)\end{array}$ & $\begin{array}{l}10.85 \\
(4.01)\end{array}$ & $\begin{array}{c}6.27 \\
(3.89)\end{array}$ & $\begin{array}{c}3.97 \\
(0.01)\end{array}$ & $\begin{array}{c}9.69 \\
(3.27)\end{array}$ & $\begin{array}{l}10.01 \\
(1.06)\end{array}$ \\
\hline Drug-seeking- and-buying scene & $\begin{array}{l}12.38 \\
(9.96)\end{array}$ & $\begin{array}{l}11.06 \\
(3.74)\end{array}$ & $\begin{array}{c}6.69 \\
(3.83)\end{array}$ & $\begin{array}{c}3.91 \\
(0.12)\end{array}$ & $\begin{array}{c}9.71 \\
(3.25)\end{array}$ & $\begin{array}{l}10.51 \\
(1.16)\end{array}$ \\
\hline \multicolumn{7}{|l|}{ HEART RATE } \\
\hline Base line & $\begin{array}{c}75.86 \\
(10.99)\end{array}$ & $\begin{array}{c}74.20 \\
(11.20)\end{array}$ & $\begin{array}{l}76.35 \\
(7.21)\end{array}$ & $\begin{array}{l}73.42 \\
(7.09)\end{array}$ & $\begin{array}{c}83.85 \\
(13.33)\end{array}$ & $\begin{array}{c}78.31 \\
(23.33)\end{array}$ \\
\hline Inhalation-fume scene & $\begin{array}{c}74.46 \\
(11.04)\end{array}$ & $\begin{array}{c}72.34 \\
(11.65)\end{array}$ & $\begin{array}{l}73.59 \\
(6.61)\end{array}$ & $\begin{array}{l}74.71 \\
(7.99)\end{array}$ & $\begin{array}{c}78.92 \\
(14.25)\end{array}$ & $\begin{array}{c}76.52 \\
(19.18)\end{array}$ \\
\hline Drug-seeking- and-buying scene & $\begin{array}{c}74.27 \\
(11.97)\end{array}$ & $\begin{array}{c}72.90 \\
(11.15)\end{array}$ & $\begin{array}{l}76.04 \\
(7.96)\end{array}$ & $\begin{array}{l}74.08 \\
(7.31)\end{array}$ & $\begin{array}{c}77.92 \\
(12.68)\end{array}$ & $\begin{array}{c}76.10 \\
(15.62)\end{array}$ \\
\hline
\end{tabular}


Wilcoxon's signed-range test was used to compare the pre- and post-treatment differences in the experimental and control groups. This test is the best alternative to the parametric Student-Fisher test for related groups, because it uses not only the signs, but also the magnitude of the differences (Manzano, 1995).

When significant differences were found between preand post-treatment, Wilcoxon's test was again used to compare the differences between pretreatment and the sixmonth follow-up.

\section{Results}

Results of the psychophysiological responses are displayed in Table 4.

\section{Skin Temperature}

In the experimental group, there were no significant preand post-treatment differences in the skin-temperature change scores. In the fume-inhalation scene, the increase in skin temperature was higher at post- than at pre-treatment but the difference was not statistically significant, $Z=-1.49, p=.06$.

In the control group, significant pre- and post-treatment differences in the skin-temperature change scores were revealed only in the fume-inhalation scene, $Z=-1.78, p=.03$.

\section{$S C L$}

In the experimental group, the increase in SCL observed while watching the video was significantly lower at posttreatment than at pre-treatment, both for the fume-inhalation scene, $Z=-2.42, p=.01$, and for the drug-seeking-andbuying scene, $Z=-2.07, p=.01$. At the 6 -month followup, this lower increase was also observed in both scenes: the fume-inhalation scene, $Z=-1.78, p=.03$, and the drugseeking-and-buying scene, $Z=-1.78, p=.03$.

There were no differences in the control group.

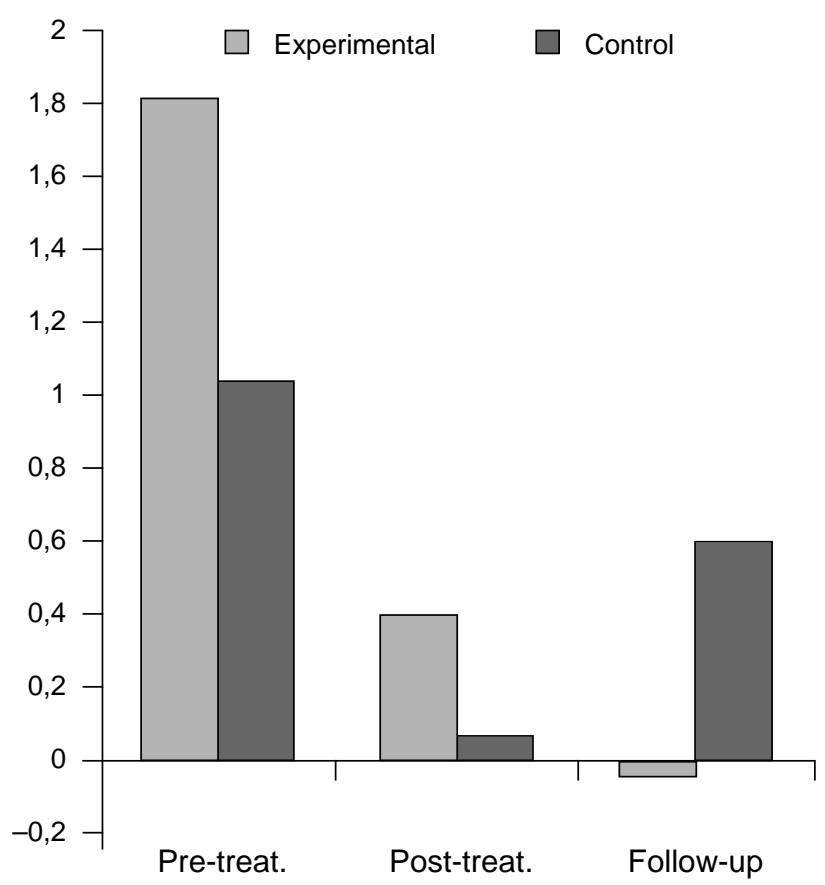

Figure 1. Changes in SCR from base line to inhalation-fume scene. Experimental $=$ Cue-exposure treatment; Control $=$ Control group; Pre-treat. $=$ pre-treatment assessment; Post-treat. $=$ post-treatment assessment; Follow-up = follow-up assessment.

Table 5

Subjective Measures, Means and Standard Deviations (in brackets)

\begin{tabular}{ccccccc}
\hline & \multicolumn{2}{c}{ PRETREATMENT } & \multicolumn{2}{c}{ POSTTREATMENT } & \multicolumn{2}{c}{ FOLLOW-UP } \\
\cline { 2 - 7 } & Experimental & Control & Experimental & Control & Experimental & Control \\
\hline CRAVING & & & & & & \\
Before watching the videotape & 8.33 & 2.5 & 3.33 & 1.66 & 6.66 & 0 \\
& $(18.50)$ & $(8.66)$ & $(10.00)$ & $(4.68)$ & $(16.32)$ & \\
After watching the videotape & 10 & 4.16 & 4.44 & 3.33 & 6.66 & 0 \\
& $(17.5)$ & $(14.43)$ & $(13.33)$ & $(8.16)$ & & \\
NEGATIVE AFFECT & & & & & & \\
Before watching the videotape & 1.73 & 1.42 & 1.64 & 1.13 & 1.58 & 1.05 \\
After watching the videotape & $(1.42)$ & $(0.15)$ & $(0.65)$ & $(0.19)$ & $(0.83)$ & $(0.19)$ \\
& 1.71 & 1.54 & 1.67 & 1.15 & 1.45 & 1 \\
POSITIVE AFFECT & $(0.40)$ & $(0.59)$ & $(0.77)$ & $(0.19)$ & $(0.76)$ & \\
Before watching the videotape & 3.15 & 2.61 & 2.87 & 2.91 & 3.15 & 2.65 \\
After watching the videotape & $(0.53)$ & $(0.65)$ & $(0.3)$ & $(0.46)$ & $(0.74)$ & $(0.35)$ \\
& 2.76 & 2.42 & 2.84 & 2.70 & 3.01 & 2.65 \\
& $(0.29)$ & $(0.75)$ & $(0.47)$ & $(0.57)$ & $(0.71)$ & $(0.07)$ \\
\hline
\end{tabular}




\section{Heart Rate}

No statistically significant differences were observed either in the experimental or the control group.

\section{Subjective Craving}

At post-treatment, after the videotape presentation, the experimental group showed less subjective craving than at pre-treatment but the difference was not statistically significant, $Z=1.34, p=.08$. The control group showed a similar craving in the post- and in the pre-treatment, with no significant differences.

\section{Negative Affect}

After the videotape presentation, both the experimental and the control group showed less negative affect at posttreatment than at pre-treatment $(Z=-2.66, p=.01$, and $Z$ $=-2.20, p=.019$, for the experimental group and the control group, respectively).

At the 6-month follow-up, only the experimental group showed less negative affect than at pre-treatment, $Z=-1.61$, $\mathrm{p}=.05$.

\section{Positive Affect}

At post-treatment, the experimental group showed less decrease after watching the video than at pretreatment, $Z=$ $-2.66, p=.01$. The control group showed a similar positive affect in the post- and in the pre-treatment.

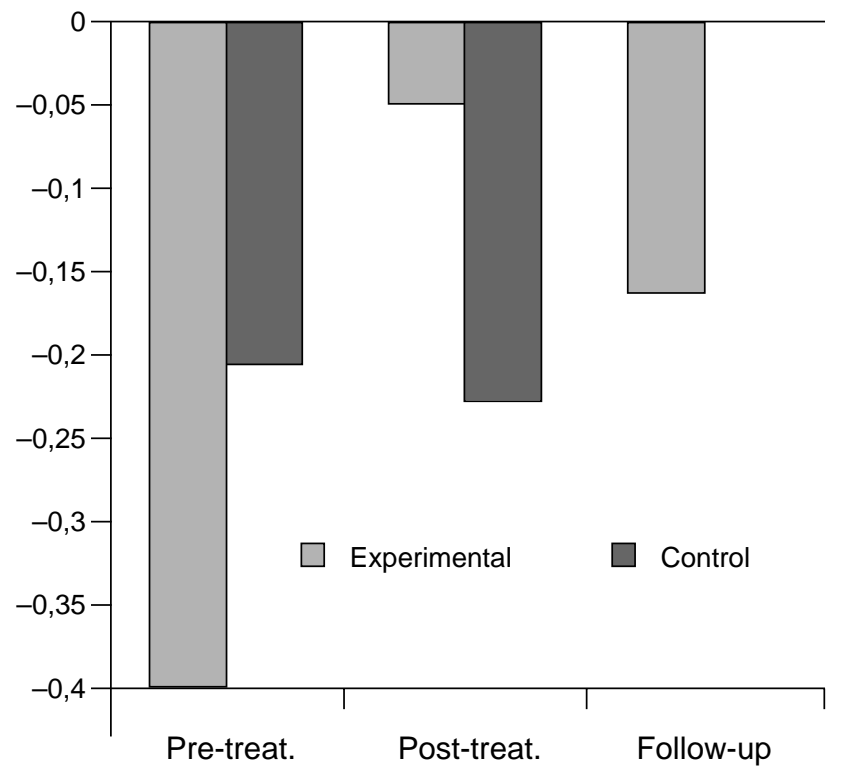

Figure 2. Changes in positive affect before and after watching the videotape. Experimental $=$ Cue-exposure treatment; Control $=$ Control group; Pre-treat. = pre-treatment assessment; Post-treat. = post-treatment assessment; Follow-up $=$ follow-up assessment.

\section{Discussion}

The major findings of the present research were that the cue-exposure treatment was effective in reducing arousal which opiate addicts displayed to the presentation of drug-related stimuli, as measured by subjective and psychophysiological responses (SCL and positive affect).

The cue exposure program was effective with regard to the following outcomes:

Reduction of SCL to drug-related stimuli. Before treatment, addicts showed an increase in SCL to drug-related stimuli. These results are in accordance with those obtained by other authors at pre-treatment (Childress et al., 1984, 1986a, 1986b; Sideroff \& Jarvik, 1980).

As expected, after treatment and at the 6-month followup, in the experimental group, this increase in SCL was significantly lower than before treatment in both scenes (fume inhalation and drug-seeking-and-buying). There were no changes in the control group's SCL. That is, those addicts who were exposed to drug-related stimuli showed a lower SCL at post-treatment, therefore, the conditioned response to the drug-related stimuli was reduced, insofar as the SCL was concerned.

Other studies have found no differences in skin conductance after a cue-exposure program (Childress et al., 1984, 1986a; Legarda, 1992; Muñoz-Rivas, 1997). Nevertheless, in the current research, SCL was the psychophysiological measure that showed more sensitivity and larger differences. The results are coherent with Powell et al.'s (1990) hypothesis, in which they state that addicts who experience craving also experience a simultaneous general arousal.

From the point of view of psychophysiological assessment, SCL is the most sensitive, fastest, and suitable response to assess the arousal of the autonomic nervous system. Therefore, SCL also should be the best psychophysiological measure to assess arousal response to drug-related stimuli. SCL is also easy to assess in the daily clinical practice, because it is not invasive, the instruments required are not expensive, and there is no electric interference.

Improvement of the affective state following the presentation of drug-related stimuli. Before treatment, slightly more decrease in positive affect was observed in the experimental group than in the control group. As expected, this decrease in positive affect was reduced in the experimental group after treatment, but not in the control group.

Positive emotional states have scarcely been used in assessment of the addict's mood: It was more usual to assess negative affect. As the presence of craving, especially after treatment, is contrary to the addict's goals and also to the messages received from the treatment center, addicts will often conceal their negative affect. 
However, they do provide information about positive emotional states. In other words, the addict is less fearful to acknowledge changes in positive rather than negative emotional states.

In our study, after cue-exposure treatment, the experimental group showed a significantly smaller decrease in positive affect than at pretreatment.

Although positive affect has not been used frequently as a measure, Legarda (1992) and Dawe et al. (1993) also observed an increase of positive emotional state. Legarda interpreted the increase in the Vigor scale of the Profile of Mood States (POMS; McNair, Lorr, \& Droppleman, 1981) as sensitization to appetitive properties of the stimuli, because addicts also showed an increase in SCL. However, in the current research, the addicts from the experimental group, in addition to showing a smaller decrease in positive affect after the presentation of the stimuli, showed also a lower SCL to drug-related stimuli.

The results also showed several unexpected results with regard to:

Skin temperature. Whereas a decrease in skin temperature to drug-related scenes was expected, an increase was observed, which would correlate with a decrease in arousal. Before treatment, both groups showed an increase in skin temperature to drug-related stimuli. After cue-exposure treatment, the experimental group did not show any significant increase in skin temperature. On the other hand, control group showed a significant increase to the fumeinhalation scene.

According to Childress et al. (1984, 1986a, 1986b), temperature is the most reliable and specific index to assess addicts' psychophysiological changes. Our results are not in accordance with Childress et al.'s (1986a, 1986b) results. There were differences in the method which they used to assess psychophysiological measures. Whereas they assessed addicts in an environmentally controlled laboratory session, we assessed addicts in the same treatment center because we wanted to develop an assessment procedure that would be useful in the clinical practice.

Heart rate. It was expected that the cue-exposure treatment would reduce the increase in heart rate to drugrelated scenes. However, before treatment, both groups showed a slight decrease in heart rate to drug-related scenes. Whereas some studies have found evidence of an increase in heart rate to drug-related stimuli (Arce, 1995; Legarda, Bradley, \& Sartory, 1990; Muñoz-Rivas, 1997; Sideroff \& Jarvik, 1980), others have not observed significant differences (Childress et al., 1984, 1986a, 1986b; Legarda et al., 1987).

After cue-exposure treatment, neither of the groups showed significant differences in heart rate. This result is in accordance with those obtained by other authors (Childress et al., 1984, 1986a, 1986b; Legarda, 1992).
Subjective craving. It was expected that the cue-exposure program would reduce the increase in subjective craving after watching drug-related scenes. However, before treatment, addicts reported a low level of craving after watching drug-related scenes. In general, other studies have observed significant increases in craving to drug-related stimuli (Bradley \& Moorey, 1988; Childress et al., 1984, 1986a, 1986b; Kasviskis, Bradley, Powell, Marks, \& Gray, 1991; McLellan et al., 1986; Muñoz-Rivas, 1997; O’Brien, Childress, McLellan, \& Ehrman, 1990; Powell, Gray, \& Bradley, 1993; Powell et al., 1990), although some studies have not found significant differences (Arce, 1995; Dawe et al., 1993; Legarda, 1992; Moring \& Strang, 1989), attributing the results to the fact that the addicts do not acknowledge or are afraid to acknowledge craving, mainly because they are in treatment and are receiving messages aimed at abstinence.

After treatment, neither of the groups showed significant differences in subjective craving after watching drug-related scenes, probably because at pre-treatment, the addicts already showed a low level of craving. Although the experimental group showed less craving at post-treatment, this difference was nonsignificant.

Exposure to a videotape in a clinical context may be insufficient to produce subjective craving. Although drugrelated scenes produce changes in SCL, they may be too weak and insufficient for the addict to identify these changes in arousal as craving. In fact, during the cue-exposure program, when addicts were exposed to real stimuli, they showed external indicators (upset stomach, nausea, etc.) and they reported subjective craving.

Negative affect. It was expected that the cue-exposure program would reduce the increase in negative affect after watching drug-related scenes. However, before treatment, the experimental group showed a similar score before and after watching drug-related scenes, and the control group showed an increase in negative affect. Other studies have reported increases in scores of negative emotional states (Arce, 1995; Dawe et al., 1993; Powell et al., 1990).

After cue-exposure treatment, the experimental and control groups showed a significant decrease in negative affect, so the expected results cannot be attributed to the cue-exposure technique. The mere repetition of the scenes may produce less negative affect.

Doubtless, more positive results would be achieved if certain improvements in the assessment procedure were made, as for example, the use of in vivo exposure to stimuli to assess craving without losing the standardized procedure.

Nevertheless, the present intervention program provides a group cue-exposure procedure that can be considered to be effective in reducing craving, as measured by SCL and positive affect. Furthermore, this treatment format has been designed to integrate exposure technique in actual programs for addictive disorders. 


\section{References}

Arce, F. (1995). Respuestas psicofisiológicas y de autoinforme de adictos a la heroína ante situaciones relacionadas y no relacionadas con drogas. Unpublished doctoral dissertation. Universidad Complutense de Madrid.

Arce, F., Bernaldo de Quirós, M., \& Labrador, F.J. (1994). Diseño de una sesión de evaluación psicofisiológica para drogodependientes ante material audiovisual. Cuadernos de Medicina Psicosomática, 32, 6-13.

Bernaldo de Quirós, M., Arce, F., \& Labrador, F.J. (2002). La evaluación del deseo de consumo condicionado a estímulos relacionados con drogas [Evaluation of craving related to conditioned drug stimuli]. International Journal of Psychology and Psychological Therapy, 2, 237-252.

Bradley, B.P., \& Moorey, S. (1988). Extinction of craving during exposure to drug-related cues: Three single case reports. Behavioural Psychotherapy, 16, 45-56.

Childress, A.R. (1991, February). Integrating cue exposure techniques with standard psychological treatment for cocaine dependence. Presented at the NIDA/ARC Symposium on Craving.

Childress, A.R., McLellan, A.T., \& O’Brien, C.P. (1984), Measurement of conditioned withdrawal-like responses in opiate dependent patients. Problems of Drug Dependence. National Institute on Drug Abuse. Research Monograph 49, 212-219.

Childress, A.R., McLellan, A.T., \& O’Brien, C.P. (1986a). Nature and incidence of conditioned responses in a methadone population: A comparison of laboratory, clinic and naturalistic settings. Problems of Drug Dependence. National Institute on Drug Abuse. Research Monograph 67, 366-372.

Childress, A.R., McLellan, A.T., \& O'Brien, C.P. (1986b). Abstinent opiate exhibit conditioned craving, conditioned withdrawal and reductions in both through extinction. British Journal of Addiction, 81, 655-660.

Dawe, S., Powell, J., Richards, D., Gossop, M., Marks, I., Strang, J., \& Gray, J.A. (1993). Does post-withdrawal cue exposure improve outcome in opiate addicts? A controlled trial. Addiction, $88,1233-1245$.

Derogatis, L.R. (1983). SCL-R: Administration, scoring and procedures manual for the $R$ (evised) version. Towson, MD: Clinical Psychometric Research.

Drummond, D.C., Troy, C., \& Glautier, S.P. (1990). Conditioned learning in alcohol dependence: Implications for cue exposure treatment. British Journal of Addiction, 85, 725-743.

J\&J Enterprises (1988). USE language and PC interface. San Francisco, CA: Applied Psychophysiology Institutes.

Kasviskis, Y., Bradley, B., Powell, J., Marks, I., \& Gray, J.A. (1991). Postwithdrawal exposure treatment to prevent relapse in opiate addicts: A pilot study. The International Journal of the Addictions, 26, 1187-1195.

Legarda, J.J. (1992). Experimental study about craving and heroin addiction treatment. London: Psychology Department. Psychiatry Institute
Legarda, J.J., Bradley, B.P., \& Sartory, G. (1987). Subjective and psychophysiological effects of drug-related cues in drug users. Journal of Psychophysiology, 4, 393-400.

Legarda, J.J., Bradley, B.P., \& Sartory, G. (1990). Effects of drugrelated cues in current and former opiate users. Journal of Psychophysiology, 4, 25-31.

Manzano, A. (1995). Inferencia estadística. Aplicaciones con SPSS/PC+. Madrid: Ra-Ma.

Marlatt, G.A. (1990). Cue exposure and relapse prevention in the treatment of addictive behaviors. Addictive Behaviors, 15, 397401.

McLellan, A.T., Childress, A.R., Ehrman, R., \& O’Brien, C.P. (1986). Extinguishing conditioned responses during opiate dependence treatment: Turning laboratory findings into clinical procedures. Journal of Substance Abuse Treatment, 3, 33-40.

McNair, D.M., Lorr, M., \& Droppleman, L.F. (1971/81). Profile of Mood States Manual. San Diego, CA: Educational and Industrial Testing Service.

Moring, J., \& Strang, J. (1989). Cue exposure as an assessment technique in the management of a heroin addict: Case report. Drug and Alcohol Dependence, 24, 161-167.

Muñoz-Rivas, M. (1997). Aplicación de la técnica de exposición en un caso de adicción a la heroína. Adicciones, 9, 347-362.

O'Brien, C.P., Childress, A.R., McLellan, A.T., \& Ehrman, R. (1990). Integrating systematic cue exposure with standard treatment in recovering drug dependent patients. Addictive Behaviors, 15, 355-365.

O’Brien, C.P., Greenstein, R., Ternes, J., McLellan, T., \& Grabowski, J. (1979). Unreinforced self-injections: Effects of rituals and outcomes in heroin addicts. Problems of Drug Dependence. CPDD Proceedings. NIDA Research Monograph 27.

Powell, J., Gray, J., \& Bradley, B. (1993). Subjective craving for opiates: Evaluation of a cue exposure protocol for use with detoxified opiate addicts. British Journal of Clinical Psychology, 32, 39-53.

Powell, J., Gray, J.A., Bradley, B., Kasviskis, Y., Strang, J., Barrat, L., \& Marks, I. (1990). The effects of exposure to drug-related cues in detoxified opiate addicts: A theoretical review and some new data. Addictive Behaviors, 15, 339-354.

Rankin, H., Hodgson, R., \& Stockwell, T. (1979). The concept of craving and its measurement. Behavioral Research and Therapy, 17, 389-396.

Sideroff, S.I., \& Jarvik, M.E. (1980). Conditioned responses to a videotape showing heroin-related stimuli. The International Journal of the Addictions, 15, 529-536.

Watson, D., Clark, L.A., \& Tellegen, A. (1988). Development and validation of brief measures of positive and negative affect: The PANAS scales. Journal of Personality and Social Psychology, 54, 1063-1070.

Received January 26, 2004

Review received March 29, 2005 Accepted April 11, 2005 